\title{
Selective control of endothelial cell proliferation with a synthetic dimerizer of FGF receptor-1
}

\author{
Marilyn B Nourse ${ }^{1,2,3}$, Marsha W Rolle ${ }^{4}$, Lil M Pabon ${ }^{2,3}$ and Charles E Murry ${ }^{1,2,3}$
}

Basic fibroblast growth factor (bFGF) is a potent angiogenic molecule, but its therapeutic use is limited by mitogenic effects on multiple cell types. To specifically activate FGF signaling in endothelial cells, a chimeric FGF receptor was generated that contained a modified FK506 drug-binding domain (F36V) fused to the FGF receptor-1 (FGFR1) cytoplasmic domain. Human umbilical vein endothelial cells (HUVECs) and human microvascular endothelial cells were retrovirally transduced with this chimeric receptor, and the effects of administering synthetic receptor-dimerizing ligands were studied. As expected, both control and transduced cells proliferated in response to bFGF treatment; however, only transduced endothelial cells exhibited dose-dependent proliferative responses to dimerizer treatment. Dimerizer-induced proliferation was MEK-dependent and was accompanied by MAP kinase phosphorylation, indicating that the chimeric receptor utilizes signaling pathways similar to endogenous FGFR1. Although bFGF stimulated wound re-epithelialization in HUVECs (which natively express FGFR1 and FGFR4), chemical dimerization of FGFR1 did not; this suggests FGFR4 may control migration in these cells. The ability to selectively activate receptor subtypes should facilitate the study of signaling pathways in vitro and in vivo beyond what can be accomplished with nonselective natural ligands, and it may eventually permit stimulation of graft cell angiogenesis without driving overgrowth of host cells.

Laboratory Investigation (2007) 87, 828-835; doi:10.1038/labinvest.3700597; published online 18 June 2007

KEYWORDS: chemically induced dimerization; endothelial cells; FGFR1; FGFR4; migration; proliferation

Revascularization therapy has the potential to prevent longterm deterioration of tissues damaged by ischemia. ${ }^{1}$ Exogenously introduced endothelial cells could provide a source of vascular tissue for such therapies. ${ }^{2-5}$ For example, endothelial progenitor cells have been shown to augment the vascular bed of ischemic myocardium by homing, incorporating into the host vasculature, and minimizing scar formation in the damaged myocardium. ${ }^{6-9}$ However, the ability to induce proliferation of these endothelial cells once they have reached the site of injury could provide an additional level of control to optimize their therapeutic effects.

A number of growth factors are known to positively influence endothelial cell proliferation and migration. Acidic fibroblast growth factor (aFGF; FGF-1), basic FGF (bFGF; FGF-2), and the vascular endothelial growth factor family are major angiogenic growth factors, ${ }^{10,11}$ and have all been demonstrated to increase angiogenesis in vivo. ${ }^{12,13}$ However, therapeutic growth factor administration has significant drawbacks. Many different cell types express receptors for these growth factors, and thus limit the ability to specifically target a certain tissue or cell graft. Furthermore, growth factors are difficult and expensive to produce and the delivery of precise quantities to target sites can be challenging to achieve in vivo.

An alternate approach is to specifically activate growth factor receptors in genetically modified cells. In a system that has been described for a number of different cell/receptor combinations, the cytoplasmic signaling domain of the growth factor receptor of interest is fused to a modified drugbinding domain. ${ }^{14-21}$ Cells expressing this chimeric receptor are then exposed to a small synthetic bifunctional ligand (dimerizer), which binds to the drug-binding domains of two receptor molecules. The growth factor signaling domains are thus brought into close proximity, mimicking the effect of endogenous receptor activation. This system offers the advantage of specifically targeting only the genetically modified cell type of interest, while leaving other cells and tissues unaffected when administered in vitro and in vivo. ${ }^{22}$ For example, dimerization of a chimeric thrombopoietin receptor selectively induced bone marrow cell proliferation in mice ${ }^{23}$

\footnotetext{
${ }^{1}$ Department of Bioengineering, University of Washington, Seattle, WA, USA; '2Department of Pathology, Center for Cardiovascular Biology, University of Washington, Seattle, WA, USA; ${ }^{3}$ Institute for Stem Cell and Regenerative Medicine, University of Washington, Seattle, WA, USA and ${ }^{4}$ Benaroya Research Institute, Seattle, WA, USA Correspondence: Dr CE Murry, MD, PhD, Department of Pathology, Center for Cardiovascular Biology, University of Washington, 815 Mercer Street, Room 453, Seattle, WA 98109, USA. E-mail: murry@u.washington.edu
}

Received 27 September 2005; accepted 26 April 2007 
and dogs. ${ }^{24}$ Dimerization of FGF receptor-1 (FGFR1) in skeletal myoblasts induced their proliferation and prevented differentiation similar to bFGF. $^{16,19}$ Cell proliferation via chemically induced FGF receptor dimerization has also been shown in mammary ductal epithelial cells ${ }^{25}$ and prostate cancer cells. $^{26}$

In the present study, we describe a method to selectively induce FGFR1 signaling in human endothelial cells. We explore the signaling pathways induced and the effects on cell proliferation and migration.

\section{MATERIALS AND METHODS Materials}

Recombinant human bFGF was kindly donated by Scios Inc. (Sunnyvale, CA, USA). AP20187 and AP23510 (dimerizers) were provided by ARIAD Pharmaceuticals (http://www. ariad.com/regulationkits; Cambridge, MA, USA). ARIAD prefers AP23510, which is a variant of AP20187, because it is easier to synthesize. The two molecules have identical domains for binding two copies of FK506 drug-binding domain (F36V); the only difference is that AP23510 lacks a $\mathrm{CH}_{2} \mathrm{~N}\left(\mathrm{CH}_{3}\right)_{2}$ group at the center linker region of the molecule (Figure 1). The binding affinities of AP20187 and AP23510 for the F36V domain are identical to both each other and to the related dimerizer AP1903 ${ }^{27}$ (Tim Clackson, ARIAD Pharmaceuticals, personal communication). Dimerizer stocks $(3.5 \mathrm{mM})$ were maintained in $100 \%$ ethanol, stored at $-20^{\circ} \mathrm{C}$ and diluted in cell-specific basal medium $(10 \mu \mathrm{M})$ for use in cell culture studies. U0126 (Promega, Madison, WI, USA), a MEK inhibitor, was reconstituted in DMSO and used at a final concentration of $15 \mu \mathrm{M}$.

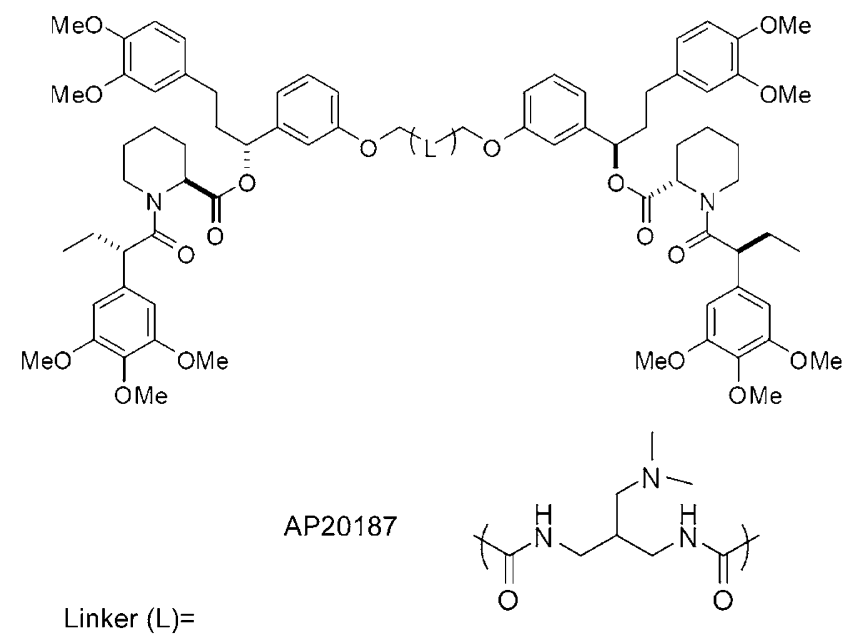

AP23510

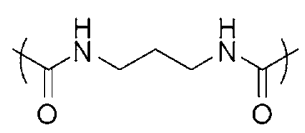

Figure 1 Chemical structures of dimerizers, AP20187 and AP23510 (ARIAD Pharmaceuticals). The two compounds have identical domains for binding two copies of F36V and differ only in their central linker region.

\section{Human Umbilical Vein Endothelial Cell Culture}

Human umbilical vein endothelial cells (HUVECs) were purchased from Cambrex (East Rutherford, NJ, USA) and cultured in endothelial growth medium, which consists of endothelial basal medium (hereafter, basal medium), supplemented with hEGF, hydrocortisone, $0.4 \%$ bovine brain extract, $2 \%$ fetal bovine serum (FBS), gentamicin, and amphotericin (hereafter, growth medium) according to the manufacturer's instructions. When cells reached $90 \%$ confluence, they were passaged and plated at $2500 \mathrm{cells} / \mathrm{cm}^{2}$ in $0.67 \%$ gelatin-coated tissue culture vessels. Cells were used between passages 5 and 9 .

\section{Human Microvascular Endothelial Cell Culture}

Human microvascular endothelial cells (HMVECs) were purchased from Cascade Biologics and cultured in Medium 131 (hereafter, basal medium) with the microvascular growth supplement (Cascade Biologics, Portland, OR, USA), supplemented with $100 \mathrm{U} / \mathrm{ml}$ penicillin G sodium, $100 \mu \mathrm{g} / \mathrm{ml}$ streptomycin sulphate, and $0.25 \mu \mathrm{g} / \mathrm{ml}$ amphotericin B (Gibco, Carlsbad, CA, USA) (hereafter, growth medium). Cells were passaged when they reached $90 \%$ confluence and replated at 5000 cells per square centimeter of surface area. Culture vessels were coated with $0.1 \%$ gelatin (Attachment Factor, Cascade Biologics) for $30 \mathrm{~min}$ at $37^{\circ} \mathrm{C}$ immediately prior to cell seeding. Cells were used between passages 4 and 10 .

\section{Construct Compositions}

The F36Vfgfr-1 construct consists of a myristylation site, the modified FKBP domain F36V, the rat FGFR1 cytoplasmic domain and a hemagglutinin epitope (HA) tag. ${ }^{16}$ Transgene expression is driven by the murine stem cell virus long terminal repeat. The bicistronic gene product encodes for enhanced green fluorescent protein (EGFP), an intraribosomal entry sequence, and the chimeric receptor. A vector encoding a myristylated, HA-tagged F36V domain lacking the FGFR1 cytoplasmic domain but otherwise identical to the F36Vfgfr-1 vector, served as a negative control where stated.

\section{Retrovirus Production}

PA317 amphotropic retroviral packaging cells were stably transduced as described previously ${ }^{16}$ with either the F36Vfgfr-1 or F36V constructs. PA317s expressing either the F36Vfgfr-1 or F36V construct were purified on a FACStar cell sorter (BD Biosciences, San Jose, CA) based on EGFP expression. Cells were grown in DMEM supplemented with $10 \%$ FBS, $2 \mathrm{mM}$ L-glutamine, 100 units $/ \mathrm{ml}$ penicillin G sodium, $100 \mu \mathrm{g} / \mathrm{ml}$ streptomycin sulfate, and $0.25 \mu \mathrm{g} / \mathrm{ml}$ amphotericin B (Gibco). Retroviral supernatant was collected after $48 \mathrm{~h}$, centrifuged at 1500 r.p.m. to remove any contaminating cells, and stored at $-80^{\circ} \mathrm{C}$ until further use. 


\section{Retroviral Transduction}

HUVECs were transduced by incubation with either PA317 F36Vfgfr-1 or PA317 F36V retroviral supernatants, supplemented with an additional $10 \%$ FBS and $8 \mu \mathrm{g} / \mathrm{ml}$ polybrene (Sigma). Plates were centrifuged for $30 \mathrm{~min}$ at 2500 r.p.m. $(1180 \mathrm{~g})$. The supernatant was then removed and cells were allowed to recover in their normal growth medium. This transduction process was repeated the next day. Two days later the cells were sorted for EGFP expression on a FACStar cell sorter. EGFP + cells were collected under sterile conditions and replated into fresh growth medium.

HMVECs were transduced by incubation with PA317 F36Vfgfr-1 retroviral supernatant supplemented with an additional $10 \% \mathrm{FBS}$, and $10 \mu \mathrm{g} / \mathrm{ml}$ lipofectamine (Invitrogen, Carlsbad, CA, USA). After an overnight incubation, cells were rinsed with Versene $(0.5 \mathrm{mM}$ EDTA and $1.1 \mathrm{mM}$ dextrose in calcium-free PBS) and then returned to their normal growth medium. Two days later, the transduction process was repeated. Cells were allowed to recover for 2 additional days and then sorted by FACS as described above.

\section{Proliferation Assays}

Endothelial cell proliferation was measured using Alamar Blue (Biosource International, Camarillo, CA, USA), a soluble oxidation/reduction indicator. ${ }^{28}$ After $4 \mathrm{~h}$ of incubation in a $10 \% \mathrm{v} / \mathrm{v}$ solution, the spectral properties of the sample were measured either by visible light (absorbance measured at 570 and $600 \mathrm{~nm}$ ) or fluorescence (excitation at $395 \mathrm{~nm}$, absorbance at $540 \mathrm{~nm}$ ). These absorbance values were then used to calculate percent reduction, which is proportional to viable cell number. Relative cell number was calculated by normalizing the values for all groups tested to the negative control/no additive group.

F36V negative control and F36Vfgfr-1 HUVECs were plated at $5 \times 10^{3}$ cells/well of a gelatin-coated 24 -well plate. Cells were grown in basal medium $+1 \%$ FBS with the addition of various treatments $(10 \mathrm{ng} / \mathrm{ml}$ bFGF, $10 \mathrm{nM}$ AP23510, $100 \mathrm{nM} \mathrm{AP23510,1} \mu \mathrm{M}$ AP23510), with one media change on the second day. The wells were then assayed for cell number after 3 days.

Wild-type and F36Vfgfr-1 HMVECs were plated at $10^{4}$ cells/well of a gelatin-coated 24 -well plate. Cells were grown in basal medium containing 1\% FBS with additional additives ( $1 \mathrm{ng} / \mathrm{ml}$ bFGF, $10 \mathrm{nM}$ AP20187, $100 \mathrm{nM}$ AP20187, $1 \mu \mathrm{M}$ AP20187, growth medium), given one media change after 2 days, and then assayed for cell number after 3 days. To study the effect of inhibiting MEK in HMVEC proliferation, cells were plated in growth medium at $10^{4}$ cells/well and serum starved in basal medium $+0.1 \%$ bovine serum albumin (BSA, MP Biomedicals, Irvine, CA, USA) overnight. The following day, the serum-free medium was removed and cells were incubated with $15 \mu \mathrm{M}$ U0126 or an equal volume of DMSO (control). After $15 \mathrm{~min}$, dimerizer was added to the treated wells. Relative cell number was determined $48 \mathrm{~h}$ later.
To compare the proliferative effects of the two different dimerizers, F36Vfgfr-1 HUVECs and HMVECs and their negative controls were placed into proliferation assays as described above in the presence of $100 \mathrm{nM}$ AP20187, $100 \mathrm{nM}$ AP23510, or no additive. Cell number was determined at 2 days for HUVECs and at 3 days for HMVECs by Alamar Blue reduction as described above.

\section{RT-PCR for FGFR Isoforms}

RNA was collected from HMVECs and HUVECs for RT-PCR analysis using Qiagen RNeasy kits. RNA was reverse transcribed to cDNA using random priming and Superscript II (Invitrogen). RNA, random primers (Promega, Madison, $\mathrm{WI}$ ), and first strand buffer (Invitrogen), were combined, incubated at $90^{\circ} \mathrm{C}$ for $2 \mathrm{~min}$, cooled to $42^{\circ} \mathrm{C}$ and then combined with dNTPs (Promega), DTT (Invitrogen), RNase inhibitor (Invitrogen), and Superscript II at $42^{\circ} \mathrm{C}$ for $60 \mathrm{~min}$. The mixture was then heated to $96^{\circ} \mathrm{C}$ for $5 \mathrm{~min}$ and the resulting cDNA was stored at $-20^{\circ} \mathrm{C}$ until further use.

Primers for the four different human FGFR isoforms were: FGFR1-sense: AAC CTC TAA CTG CAG AAC TGG GAT G; FGFR1-antisense: AGT CCA TTA TGA TGC TCC AGG TGG C; FGFR2-sense: CGC GCT CTG AGC CTT CGC AAC TC; FGFR2-antisense: GTG GTA TCC TCA ACT AAA CTG AAG GAG G; FGFR3-sense: CCA GCG GCT GCA GGT GCT GAA TG; FGFR3-antisense: GCA CGT CCA GAG TGT ACG TCT GCC; FGFR4-sense: AGC AGC AAG AGC AGG AGC TGA CAG; FGFR4-antisense: CGA AGC TGC TGC CGT TGA TGA CG. Primers were obtained from Gibco BRL (Carlsbad, CA, USA). Expected product sizes were 677 and $410 \mathrm{bp}$ for FGFR1, 533 bp for FGFR2, 464 bp for FGFR3, and 768 bp for FGFR4. Multiple splice variants of FGFR1 account for the different amplicon sizes.

To detect the presence of FGFR isoforms, primers and cDNA were combined with dNTPs, Taq polymerase, $2.25 \mathrm{mM}$ $\mathrm{MgCl}_{2}$, and $\times 10 \mathrm{MgCl}_{2}$-free buffer (Promega). Polymerase chain reaction $(\mathrm{PCR})$ cycle times and temperatures were as follows: $95^{\circ} \mathrm{C}$ for $5 \mathrm{~min}, 30$ cycles of $94^{\circ} \mathrm{C}$ for $1 \mathrm{~min}, 65^{\circ} \mathrm{C}$ for $1 \mathrm{~min}$, and $72^{\circ} \mathrm{C}$ for $1 \mathrm{~min}$, followed by a $5 \mathrm{~min} 72^{\circ} \mathrm{C}$ extension step. Restriction enzyme digestion confirmed the identity of the PCR products (data not shown). cDNA from differentiated human embryonic stem cells served as a positive control for all four isoforms.

\section{Western Blotting for ERK Activation}

F36V and F36Vfgfr-1 HUVECs were grown in six-well plates and serum starved overnight (basal medium $+0.5 \%$ BSA). Medium was exchanged, and then $10 \mathrm{ng} / \mathrm{ml}$ bFGF, $100 \mathrm{nM}$ AP20187, or $100 \mathrm{nM}$ AP23510 was added to the wells. Cells were incubated for $1 \mathrm{~h}$ and then lysed as described below.

Wild-type and F36Vfgfr-1 HMVECs were grown in sixwell plates and serum starved (basal medium $+0.1 \%$ BSA) overnight. Medium was exchanged, and then $1 \mathrm{ng} / \mathrm{ml}$ bFGF, $100 \mathrm{nM}$ AP20187, or $100 \mathrm{nM}$ AP23510 was added to 
the wells. Cells were incubated for $1 \mathrm{~h}$ and then lysed as described below.

Protein was harvested in Western sample buffer $(50 \mathrm{mM}$ Tris- $\mathrm{HCl}, 1 \%$ SDS, $10 \%$ glycerol), containing protease inhibitors (complete protease inhibitor cocktail tablets, Roche Applied Science, Indianapolis, IN, USA) and phosphatase inhibitors (sodium fluoride, sodium pyrophosphatate, and sodium orthovanadate, each at $1 \mathrm{mM}$ concentration). DNA was sheared by passing the lysate through a $22 \mathrm{G}$ needle 10 times. Protein concentration was assayed with a MicroBCA kit (Pierce Biotechnology, Rockford, IL, USA). Samples ( $25 \mu \mathrm{g} /$ lane) were loaded into pre-cast $4-15 \%$ polyacrylamide gels (BioRad, Hercules, CA, USA), separated by SDS-polyacrylamide gel electrophoresis (SDS-PAGE), and transferred onto a Hybond-ECL nitrocellulose membrane (Amersham Biosciences, Piscataway, NJ, USA). The membranes were blocked (20 mM Tris $\mathrm{HCl}, 500 \mathrm{mM} \mathrm{NaCl}, 0.05 \%$ Tween-20, and $5 \%$ Carnation nonfat dry milk) for $1 \mathrm{~h}$ at room temperature and probed for phosphorylated ERK (1:1000, Cell Signalling Technology, Beverly, MA, USA) overnight at $4^{\circ} \mathrm{C}$. Membranes were then washed with TBS-T $(20 \mathrm{mM}$ Tris- $\mathrm{HCl}, 300 \mathrm{mM} \mathrm{NaCl}, 0.1 \%$ Tween-20), incubated with the secondary antibody (horse radish peroxidase (HRP)conjugated goat anti-rabbit, 1:7500, Jackson ImmunoResearch, West Grove, PA, USA), and developed using SuperSignal West Dura (Pierce Biotechnology). Blots were visualized by exposure to ECL film (Hyperfilm ECL, Amersham Biosciences).

Following exposure for the phospho-ERK blots, the membranes were stripped with two 30 -min room temperature washes in stripping buffer $(100 \mathrm{mM}$ glycine, $0.1 \% \mathrm{SDS}$, $1 \%$ Tween-20 ( $\mathrm{pH} 2.8)$ ). Membranes were re-blocked and incubated with a pan-ERK polyclonal antibody (1:1000, Chemicon, Temecula, CA, USA) and secondary antibody (HRP-conjugated goat anti-rabbit, 1:50 000), and then developed and exposed as described above.

\section{Migration Assay}

F36V and F36Vfgfr-1 HUVECs were grown to confluence in gelatin-coated six-well plates and serum starved overnight in basal medium supplemented with $0.2 \%$ BSA. A cell-free path was created by dragging a $1000 \mu$ l pipet tip across the well. Cells were exposed to media containing $2 \%$ FBS and either $10 \mathrm{ng} / \mathrm{ml}$ bFGF, 10 or $100 \mathrm{nM}$ AP23510, or no additive $(n=3$ wells per group). The cell-free paths were imaged at $0,4,8$, 12, and $25 \mathrm{~h}$, using a Nikon Coolpix 995 digital camera ( 2 fields/well), measured using Scion Image analysis software (Scion Corporation, Frederick, MD, USA) in a blinded fashion, and plotted as distance migrated.

\section{Statistics}

Statistics for proliferation assays and the in vitro wound re-epithelialization assay were performed using one-way analysis of variance, followed by the Tukey-Kramer Multiple Comparison Test (InStat, GraphPad Software Inc., San Diego,
CA, USA). Results are presented as mean \pm s.e.m. Statistical significance was set at $P<0.05$.

\section{RESULTS}

\section{Chimeric Receptor Expression and Cell Selection}

HUVECs were transduced with a bicistronic vector encoding either the dimerizer-responsive FGFR1 chimeric receptor $(\mathrm{F} 36 \mathrm{Vfgfr}-1)^{16}$ or the F36V domain alone and sorted by FACS for expression of EGFP. After four passages, FACS analysis confirmed that the F36V and F36Vfgfr-1 HUVECs were 80 and 95\% EGFP +, respectively. HMVECs were similarly transfected with the F36Vfgfr-1 construct and purified based on EGFP expression. FACS analysis after two passages of HMVECs confirmed that the F36Vfgfr-1 cells were $90 \% \mathrm{EGFP}+$.

\section{F36Vfgfr-1 HUVECs and HMVECs Proliferate in Response to Dimerizer and bFGF}

In the presence of the dimerizer, F36Vfgfr-1 HUVECs proliferated at twice the rate of control cells $(P<0.001)$, whereas the F36V negative control HUVECs did not proliferate in response to dimerizer $(P>0.05$ vs untreated cells). In the presence of $10 \mathrm{ng} / \mathrm{ml}$ bFGF, both F36V and F36Vfgfr-1 HUVECs proliferated at a rate four- to fivefold higher than untreated cells (Figure 2a). The maximal dimerizer-induced proliferation, however, was only half of that seen with bFGF treatment.

HMVECs treated with $1 \mathrm{ng} / \mathrm{ml}$ bFGF proliferated at a level twofold higher than untreated cells (Figure 2b). Increasing the bFGF concentration to $10 \mathrm{ng} / \mathrm{ml}$ did not result in a greater level of proliferation in these cells (data not shown). In the presence of dimerizer, F36Vfgfr-1 HMVECs proliferated comparably to bFGF treatment $(P<0.001$ for untreated $v s$ each dimerizer concentration), whereas wildtype negative control cell numbers were equivalent to untreated samples.

To compare the effects of the two different dimerizers on cell proliferation, F36Vfgfr-1 HUVECs and HMVECs were treated with equal concentrations of AP20187 and AP23510. Both cell types responded to the two dimerizer compounds with comparable levels of proliferation $(P>0.05$ for F36Vfgfr-1 HUVEC AP20187 vs AP23510 and $P>0.05$ for F36Vfgfr-1 HMVEC AP20187 vs AP23510) (Figure 2c and d).

\section{FGFR Isoform Expression in HMVECs and HUVECs}

We hypothesized that the variation in proliferation responses to dimerizer between HMVECs and HUVECs, relative to their responses to bFGF, may be due to activation of FGF receptor isoforms in addition to FGFR1. There are four known FGFRs, ${ }^{29}$ all of which can signal in response to bFGF. $^{30}$ To determine which isoforms these cells expressed, primers for the four isoforms were designed and used to probe the cDNA of HMVECs and HUVECs. RT-PCR analysis revealed that HMVECs express only FGFR1, whereas HUVECs express both FGFR1 and FGFR4 (Figure 3). Neither 

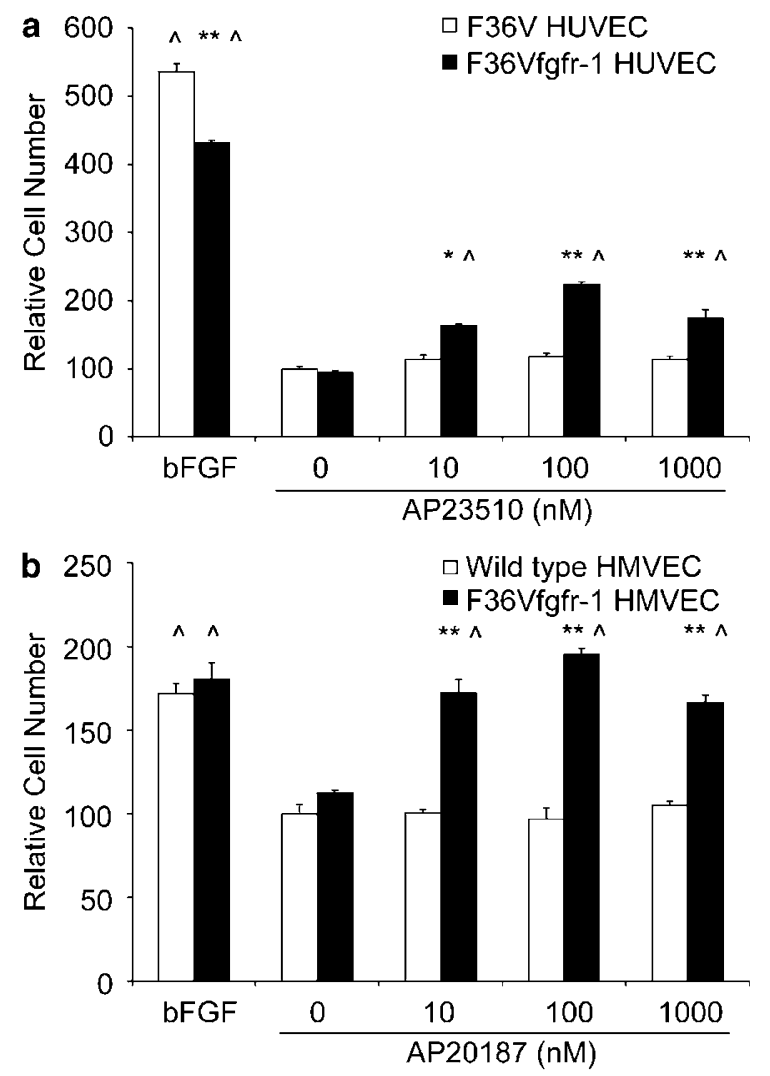

c

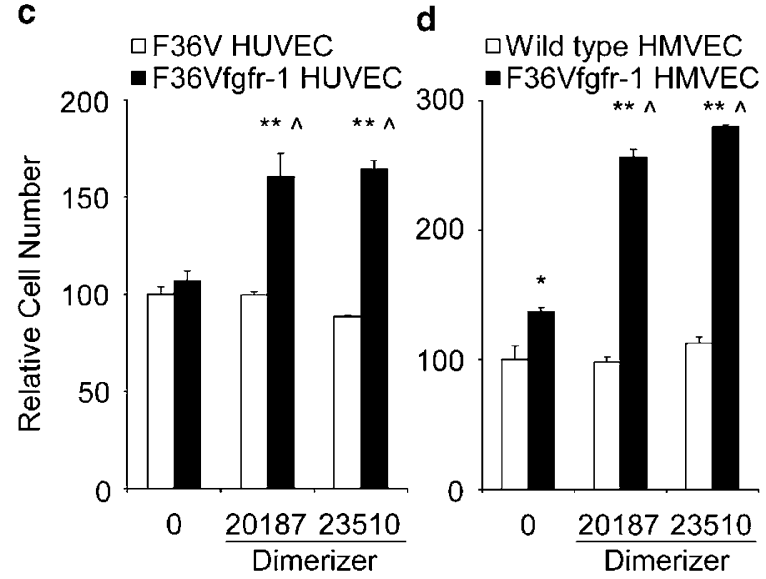

Figure 2 Dimerizer induces proliferation in F36Vfgfr-1 endothelial cells. F36V- and F36Vfgfr-1-transfected HUVECs (a) and wild-type and F36Vfgfr-1transfected HMVECs (b) were subjected to proliferation assays as described in Materials and Methods. Endothelial cells expressing the F36Vfgfr-1 receptor proliferated in response to bFGF and dimerizer, whereas negative controls responded only to bFGF. HMVECs proliferated at roughly the same level as bFGF treatment. The HUVEC response to dimerizer was less than $50 \%$ of the response to bFGF. (c, d): both HUVECs and HMVECs respond comparably to equal concentrations (100 nM) of AP20187 and AP23510. Bars represent mean \pm s.e.m. ${ }^{\star} P<0.01$ vs negative ctrl cells. ${ }^{*} P P<0.001$ vs negative ctrl cells. $\wedge P<0.01$ vs no treatment; $n=3$ per treatment group.

population expressed FGFR2 or FGFR3. This difference in receptor expression patterns between the two cell types may explain why dimerizer completely mimicked bFGF's mito-

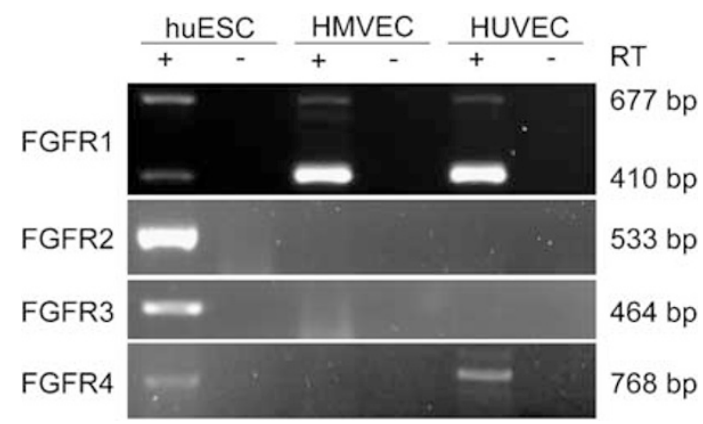

Figure 3 RT-PCR analysis of FGFR isoform expression. RT-PCR analysis performed on HMVECs and HUVECs revealed that HMVECs express only FGFR1, whereas HUVECs express both FGFR1 and FGFR4. Differentiated human embryonic stem cells (huESC) were used as a positive control. Amplicon sizes are indicated on the right-hand side. $-\mathrm{RT}$ indicates reactions where reverse transcriptase was omitted.

genic effects in HMVECs, but only partially in HUVECs (see 'Discussion').

\section{MAP Kinase Signaling Pathway is Activated in Response to bFGF and Dimerizer}

To determine whether the dimerizer-induced proliferation of HUVECs and HMVECs is mediated through similar signaling pathways, whole-cell lysates were examined for the presence of phosphorylated ERK, a downstream signaling target of FGFR1. ${ }^{11}$ HUVECs and HMVECs were serum starved overnight and then stimulated with bFGF or dimerizer for $1 \mathrm{~h}$. Protein lysates were collected, separated by SDS-PAGE, and Western blotted for either phosphorylated ERK or pan ERK. Pan ERK was used to verify equal levels of total ERK. For both HUVECs (Figure 4a) and HMVECs (Figure 4b), bFGF treatment resulted in an increase in phosphorylated ERK. Untreated cells showed only low levels of phosphorylated ERK. Treatment with dimerizer (AP20187 or AP23510) resulted in an increase in phosphorylated ERK only in F36Vfgfr-1 cells; negative control cells showed no increase of phosphorylated ERK in response to dimerizer.

\section{Blocking MEK Activity Inhibits Dimerizer-Induced Proliferation}

MEK is a MAP kinase kinase that is known to regulate proliferative signaling following FGF stimulation. To test whether our chimeric receptor signaled through this pathway, F36Vfgfr-1 HMVECs were serum starved and treated with $15 \mu \mathrm{M}$ U0126, a MEK inhibitor, and then treated with dimerizer in a proliferation assay (Figure 4c). MEK inhibition significantly decreased dimerizer-induced HMVEC proliferation $(P<0.01)$, but had no effect on the untreated controls.

\section{F36Vfgfr-1 HUVECs do not Migrate in Response to Dimerizer}

Because endothelial cells have been shown to migrate in response to $\mathrm{bFGF}^{31,32}$ we asked whether dimerizer-induced 


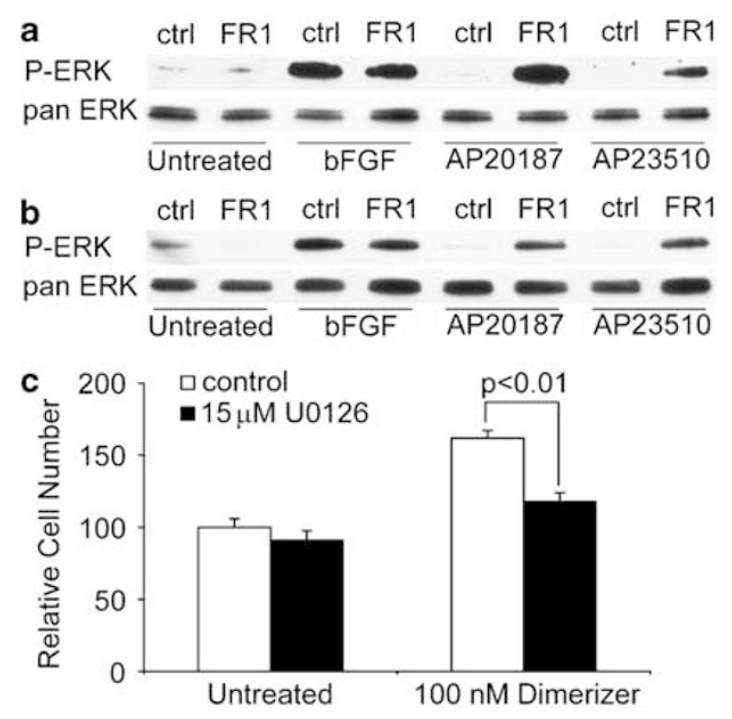

Figure 4 Dimerizer induces MAP kinase activation in F36Vfgfr-1 endothelial cells. HUVECs (a) and HMVECs (b) were serum starved overnight before addition of bFGF or dimerizer. Treatment lasted for $60 \mathrm{~min}$ and then protein was harvested. Both negative control and F36Vfgfr-1 cells phosphorylated ERK in response to bFGF treatment, but dimerizer treatment induced ERK phosphorylation only in F36Vfgfr-1 cells. (c) U0126, a MEK inhibitor, prevents dimerizer-induced proliferation in F36Vfgfr-1 HMVECs. Bars represent mean \pm s.e.m.

FGFR1 signaling could recapitulate this function. F36Vfgfr-1 and F36V HUVECs were grown to confluence in gelatincoated six-well plates and then serum starved overnight. Cells were then monitored over time for their ability to close a gap created between them in the presence of bFGF, dimerizer, or no additive. Average initial path width was $883 \pm 26 \mu \mathrm{m}$ for F36Vfgfr- 1 HUVECs and $883 \pm 33 \mu \mathrm{m}$ for F36V HUVECs.

In contrast with the positive effects detected in the proliferation and signaling data, HUVECs did not respond to dimerizer in the migration assay (Figure 5). As expected, bFGF induced both F36Vfgfr- 1 and F36V HUVECs to migrate and nearly close the gap at $25 \mathrm{~h}(759 \pm 58 \mu \mathrm{m}$ migrated for F36Vfgfr-1 HUVECs, $781 \pm 34 \mu \mathrm{m}$ for F36V HUVECs, $P<0.05)$. Contrary to our hypothesis, however, dimerizertreated F36Vfgfr-1 HUVECs were indistinguishable from the untreated group (F36Vfgfr-1 HUVEC distance migrated: no additive, $531 \pm 39 \mu \mathrm{m} ; 10 \mathrm{nM}$ AP23510, $491 \pm 32 \mu \mathrm{m} ; 100 \mathrm{nM}$ AP23510, $505 \pm 45 \mu \mathrm{m}$; F36V HUVEC distance migrated: no additive, $449 \pm 41 \mu \mathrm{m} ; 10 \mathrm{nM}$ AP23510, $512 \pm 16 \mu \mathrm{m} ; 100 \mathrm{nM}$ AP23510, $516 \pm 62 \mu \mathrm{m}$; all $P>0.05)$. Attempts to study migration of HMVECs in response to bFGF or dimerizer were unsuccessful, due to cell death and detachment under low serum conditions required by the assay (data not shown).

\section{DISCUSSION}

Tissues require an adequate blood supply for survival and function; consequently, engineering vascular networks is a valuable therapeutic goal. In particular, augmenting the vasculature of ischemic tissues, such as infarcted myocardium, has been shown to improve the function of those tissues even without replacing lost cardiomyocytes. ${ }^{2,6,7}$ The ability to stimulate exogenous vascular cells in situ with a synthetic ligand would offer advantages, such as cell targeting specificity in response to systemic dimerizer administration in vivo. Herein, we present a system to specifically activate the FGF receptor-1 (FGFR1) signaling pathway in human endothelial cells and examine the effects of synthetic dimerizing ligands AP20187 and AP23510 ('dimerizers') on cell function.

Activation of FGFR1 with the dimerizer in HUVECs and HMVECs induced similar responses with respect to cell proliferation and activation of the MAP kinase pathway (Figures 2 and 4). However, there were some differences between these cell types as well. When stimulated with dimerizer, HMVECs proliferated at a level that was about the same as with bFGF. In contrast, HUVEC proliferation in response to dimerizer was only about half of the response to bFGF, implying that perhaps the native ligand is signaling through multiple endogenous receptors in this cell type. Furthermore, HUVECs migrated well in response to bFGF, but failed to migrate in response to the dimerizer (Figure 5), suggesting that bFGF protein induced migration through a pathway independent of FGFR1. Indeed, RT-PCR analysis of HUVECs and HMVECs revealed that whereas HMVECs expressed only FGFR1, HUVECs expressed both FGFR1 and FGFR4 (Figure 3). We speculate that bFGF-induced migration in HUVECs may be activated through FGFR4, as signaling with the dimerizer-responsive FGFR1 did not induce migration, with a similar role for FGFR4 in driving enhanced proliferation in HUVECs. Basic FGF is able to bind and signal through all four FGF receptor isoforms, although not all splice variants. ${ }^{30,33,34}$ Signaling through FGFR4 has mitogenic effects on cells, similar in magnitude to FGFR1. ${ }^{34,35}$ FGFR1 and FGFR4 differ in their signaling pathways; FGFR4 only weakly stimulates the MAP kinase pathway compared to FGFR1, whereas it activates an $85-\mathrm{kDa}$ serine kinase that is not detected in FGFR1 activation. ${ }^{34}$ This is consistent with our finding of equivalent ERK activation (likely the result of FGFR1 activation), but differing levels of proliferation, depending on whether the cells expressed FGFR4. This difference demonstrates the ability of chemically induced receptor dimerization to dissect signaling pathways more precisely than can be done with natural ligands.

Our results on the role of FGFR1 in endothelial cell migration contrast with data presented by Landgren $e t a l,{ }^{36}$ who found that forced dimerization of FGFR1 by using a PDGFR$\alpha$ extracellular domain fusion protein induced migration of endothelial cells in a modified Boyden chamber chemotaxis assay. However, the cells used in that study were porcine aortic endothelial cells, so difference in species, vessel source, assay type, endogenous FGFR isoform expression, or the different receptor model used could account for the discrepancy in migratory induction.

To address the discrepancies between FGFR1 activation in HUVECs and HMVECs, we endeavored to test the ability of 

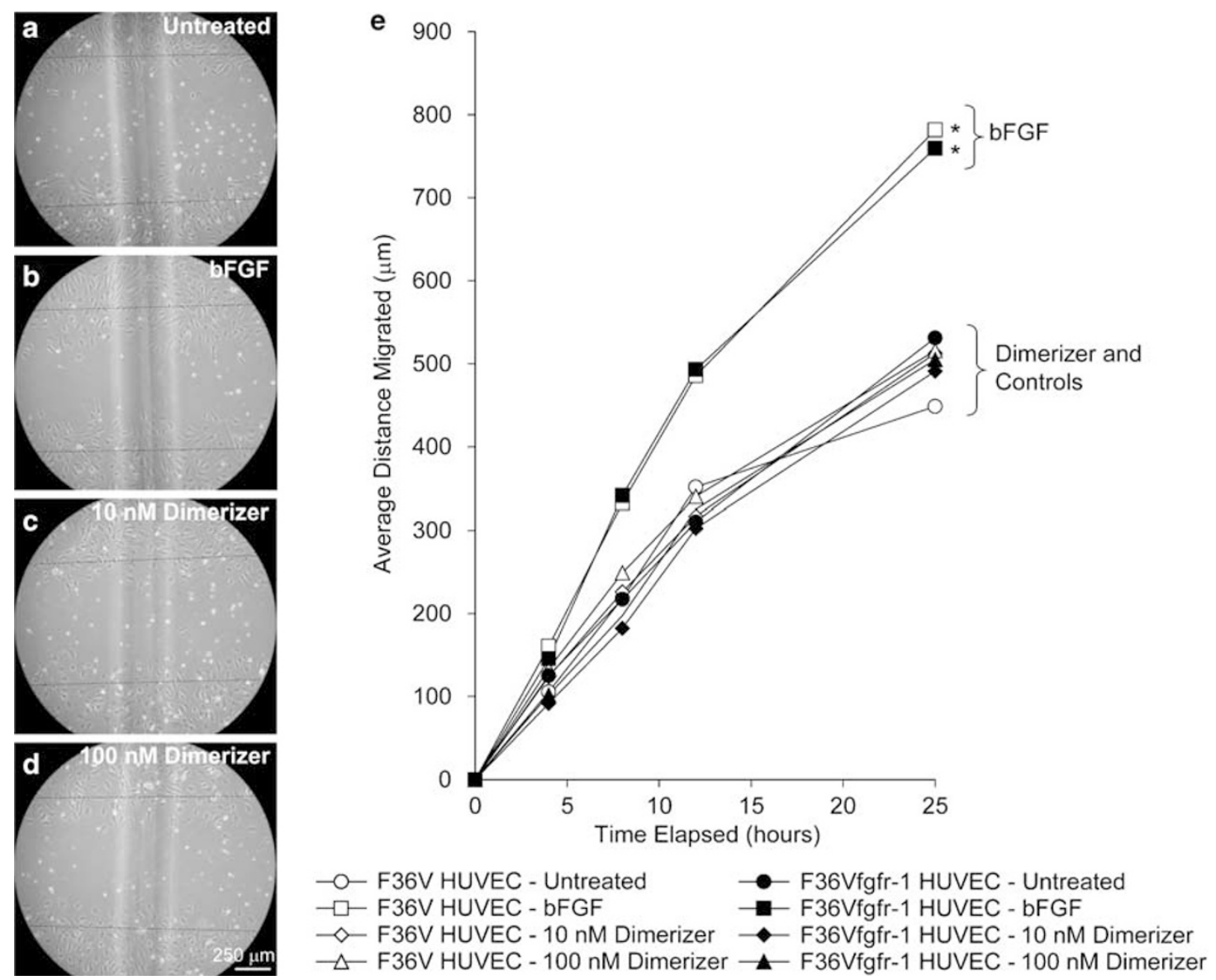

Figure 5 Dimerizer does not induce migration in F36Vfgfr-1 HUVECs. F36V and F36Vfgfr-1 HUVECs were grown to confluence in six-well plates and then serum starved overnight. A cell-free path was created by dragging a pipet tip across the well. Cells were treated with $10 \mathrm{ng} / \mathrm{ml} \mathrm{bFGF}, 10 \mathrm{or} 100 \mathrm{nM}$ AP23510, or no additive as described in 'Materials and Methods'. Representative images of F36Vfgfr-1 HUVECs in each treatment after $12 \mathrm{~h}$ of migration are shown (a-d); horizontal dashed lines indicate original cell-free path width. The vertical line in each image is a razor blade scratch made on the back of each well that was used as a landmark to take serial images of the same location. (e) Only bFGF was able to increase the rate of migration of the cells into the center of the scratch; both doses of AP23510 were indistinguishable from the untreated wells for both the negative control cells and the F36Vfgfr-1 cells. ${ }^{*} P<0.05$ vs all other treatments.

(1) F36Vfgfr-1 HMVECs to migrate in response to dimerizer and (2) a chimeric FGFR4 receptor to induce migration in HUVECs. Unfortunately, neither experiment was successful. Attempts to induce HMVEC migration failed due to extensive cell death under the low serum conditions required to test the effects of bFGF or dimerizer. A less stringent serum starvation protocol as described by Antico et al ${ }^{37}$ for HMVEC migration did not ameliorate the problem in our hands. We also attempted to test if dimerization of FGFR4 would stimulate HUVECs to migrate and proliferate as effectively as bFGF treatment. We generated a lentiviral vector encoding the F36Vfgfr- 4 receptor under the control of the chicken $\beta$ actin promoter with a CMV enhancer element (kindly provided by $\mathrm{C}$ Anthony Blau at the University of Washington). Despite success in lentiviral transduction of HUVECs with other constructs, we were unable to obtain efficiently transduced cells, even after antibiotic selection. We speculate that the chicken $\beta$-actin promoter may induce toxic levels of this receptor, resulting in either cell dysfunction or death.
In summary, we have described a system to specifically control the proliferation of two independent human endothelial cell types by mimicking the effects of FGF stimulation with a synthetic ligand. Studies of myoblasts transduced with our F36Vfgfr-1 construct grafted into infarcted hearts recently showed larger grafts and improvement in cardiac function following dimerizer administration, demonstrating that this system can be used to regulate therapeutic cell proliferation in vivo. ${ }^{19}$ Future in vivo studies with F36Vfgfr-1 endothelial cells will test whether angiogenesis in ischemic tissues can be controlled with the dimerizer system.

\section{ACKNOWLEDGEMENTS}

We thank Mr Fred Lewis for expert technical assistance with FACS sorting and Dr Jasmine Zia for help with the migration assay. The authors also thank Dr Tim Clackson and ARIAD Pharmaceuticals for providing the dimerizer compounds and $\operatorname{Dr} C$ Anthony Blau at the University of Washington for the F36Vfgfr-4 lentiviral construct. 
Funding for this work was provided by the National Institutes of Health (R24HL64387, R01HL61553, R01HL84642, P01HL03174, and T32HL07312) and the National Science Foundation (Graduate Research Fellowship to MBN).

1. Freedman $S B$, Isner JM. Therapeutic angiogenesis for coronary artery disease. Ann Intern Med 2002;136:54-71.

2. Rafii S, Lyden D. Therapeutic stem and progenitor cell transplantation for organ vascularization and regeneration. Nat Med 2003;9:702-712.

3. Kawamoto A, Tkebuchava T, Yamaguchi J, et al. Intramyocardial transplantation of autologous endothelial progenitor cells for therapeutic neovascularization of myocardial ischemia. Circulation 2003;107:461-468.

4. Kim EJ, Li RK, Weisel RD, et al. Angiogenesis by endothelial cell transplantation. J Thorac Cardiovasc Surg 2001;122:963-971.

5. Chekanov V, Akhtar M, Tchekanov G, et al. Transplantation of autologous endothelial cells induces angiogenesis. Pacing Clin Electrophysiol 2003;26:496-499.

6. Kocher AA, Schuster MD, Szabolcs MJ, et al. Neovascularization of ischemic myocardium by human bone-marrow-derived angioblasts prevents cardiomyocyte apoptosis, reduces remodeling and improves cardiac function. Nat Med 2001;7:430-436.

7. Kawamoto A, Gwon HC, Iwaguro $\mathrm{H}$, et al. Therapeutic potential of ex vivo expanded endothelial progenitor cells for myocardial ischemia. Circulation 2001;103:634-637.

8. Schachinger $\mathrm{V}$, Assmus $\mathrm{B}$, Britten $\mathrm{MB}$, et al. Transplantation of progenitor cells and regeneration enhancement in acute myocardial infarction: final one-year results of the TOPCARE-AMI Trial. J Am Coll Cardiol 2004;44:1690-1699.

9. Chavakis E, Aicher A, Heeschen C, et al. Role of beta2-integrins for homing and neovascularization capacity of endothelial progenitor cells. J Exp Med 2005;201:63-72.

10. Cross MJ, Claesson-Welsh L. FGF and VEGF function in angiogenesis: signalling pathways, biological responses and therapeutic inhibition. Trends Pharmacol Sci 2001;22:201-207.

11. Suhardja A, Hoffman H. Role of growth factors and their receptors in proliferation of microvascular endothelial cells. Microsc Res Tech 2003;60:70-75.

12. Thompson JA, Anderson KD, DiPietro JM, et al. Site-directed neovessel formation in vivo. Science 1988;241:1349-1352.

13. Cao $\mathrm{Y}$, Hong A, Schulten $\mathrm{H}$, et al. Update on therapeutic neovascularization. Cardiovasc Res 2005;65:639-648.

14. Spencer DM, Wandless TJ, Schreiber SL, et al. Controlling signal transduction with synthetic ligands. Science 1993;262:1019-1024.

15. Blau CA, Peterson KR, Drachman JG, et al. A proliferation switch for genetically modified cells. Proc Natl Acad Sci USA 1997;94:3076-3081.

16. Whitney ML, Otto KG, Blau CA, et al. Control of myoblast proliferation with a synthetic ligand. J Biol Chem 2001;276:41191-41196.

17. Li ZY, Otto K, Richard RE, et al. Dimerizer-induced proliferation of genetically modified hepatocytes. Mol Ther 2002;5:420-426.

18. Pownall ME, Welm BE, Freeman KW, et al. An inducible system for the study of FGF signalling in early amphibian development. Dev Biol 2003;256:89-99.

19. Stevens KR, Rolle MW, Minami E, et al. Chemical dimerization of fibroblast growth factor receptor-1 induces myoblast proliferation, increases intracardiac graft size, and reduces ventricular dilation in infarcted hearts. Hum Gene Ther 2007;18:401-412 [E-pub May 7, 2007].

20. Hanks BA, Jiang J, Singh RA, et al. Re-engineered CD40 receptor enables potent pharmacological activation of dendritic-cell cancer vaccines in vivo. Nat Med 2005;11:130-137.

21. Larrivee B, Lane DR, Pollet I, et al. Vascular endothelial growth factor receptor-2 induces survival of hematopoietic progenitor cells. J Biol Chem 2003;278:22006-22013.

22. Iuliucci JD, Oliver SD, Morley $S$, et al. Intravenous safety and pharmacokinetics of a novel dimerizer drug, AP1903, in healthy volunteers. J Clin Pharmacol 2001;41:870-879.

23. Jin $\mathrm{L}$, Zeng $\mathrm{H}$, Chien $\mathrm{S}$, et al. In vivo selection using a cell-growth switch. Nat Genet 2000;26:64-66.

24. Neff $\mathrm{T}$, Horn PA, Valli VE, et al. Pharmacologically regulated in vivo selection in a large animal. Blood 2002;100:2026-2031.

25. Welm BE, Freeman KW, Chen M, et al. Inducible dimerization of FGFR1: development of a mouse model to analyze progressive transformation of the mammary gland. J Cell Biol 2002;157:703-714.

26. Freeman KW, Gangula RD, Welm BE, et al. Conditional activation of fibroblast growth factor receptor (FGFR) 1, but not FGFR2, in prostate cancer cells leads to increased osteopontin induction, extracellular signal-regulated kinase activation, and in vivo proliferation. Cancer Res 2003;63:6237-6243.

27. Clackson T, Yang W, Rozamus LW, et al. Redesigning an FKBP-ligand interface to generate chemical dimerizers with novel specificity. Proc Natl Acad Sci USA 1998;95:10437-10442.

28. Ahmed SA, Gogal Jr RM, Walsh JE. A new rapid and simple nonradioactive assay to monitor and determine the proliferation of lymphocytes: an alternative to $[3 \mathrm{H}]$ thymidine incorporation assay. J Immunol Methods 1994;170:211-224.

29. Friesel RE, Maciag T. Molecular mechanisms of angiogenesis: fibroblast growth factor signal transduction. Faseb J 1995;9:919-925.

30. Ornitz DM, Xu J, Colvin JS, et al. Receptor specificity of the fibroblast growth factor family. J Biol Chem 1996;271:15292-15297.

31. Terranova VP, DiFlorio R, Lyall RM, et al. Human endothelial cells are chemotactic to endothelial cell growth factor and heparin. J Cell Biol 1985;101:2330-2334.

32. Sato Y, Rifkin DB. Autocrine activities of basic fibroblast growth factor: regulation of endothelial cell movement, plasminogen activator synthesis, and DNA synthesis. J Cell Biol 1988;107:1199-1205.

33. Eswarakumar VP, Lax I, Schlessinger J. Cellular signaling by fibroblast growth factor receptors. Cytokine Growth Factor Rev 2005; 16:139-149.

34. Vainikka S, Joukov V, Wennstrom $S$, et al. Signal transduction by fibroblast growth factor receptor-4 (FGFR-4). Comparison with FGFR-1. J Biol Chem 1994;269:18320-18326.

35. Vainikka $S$, Joukov V, Klint $P$, et al. Association of a 85-kDa serine kinase with activated fibroblast growth factor receptor-4. J Biol Chem 1996;271:1270-1273.

36. Landgren $\mathrm{E}$, Klint $\mathrm{P}$, Yokote $\mathrm{K}$, et al. Fibroblast growth factor receptor-1 mediates chemotaxis independently of direct $\mathrm{SH} 2$-domain protein binding. Oncogene 1998;17:283-291.

37. Antico G, Lingen MW, Sassano A, et al. Recombinant human uteroglobin/CC10 inhibits the adhesion and migration of primary human endothelial cells via specific and saturable binding to fibronectin. J Cell Physiol 2006;207:553-561. 